\title{
Effects of Exposure on Themed Picture Books on Children's Dietary Attitudes
}

\author{
Lu Yi-Ping, Cheng Jui-Ching ${ }^{*}$, Chou, Mei-Ju \\ Department of Early Childhood Education, National Pingtung University, Taiwan
}

Copyright $(2016$ by authors, all rights reserved. Authors agree that this article remains permanently open access under the terms of the Creative Commons Attribution License 4.0 International License

\begin{abstract}
The present study investigated whether and how themed food series of picture books integrated into preschool daily life activities and curriculum can elevate young children's healthy dietary habits. In order to realize whether young children can recognize the healthy dietary habits, understand the eating attitudes between themselves and the roles in the picture book, and identify with the healthy eating attitudes. 30 children (aged 4-6 years) and 10 of their parents participated in co-reading sessions using 10 selected themed picture books on three morning days in preschool every week for 18 weeks. These children were randomly selected from the researchers' three classes in one preschool. Within the child-centered integrated curriculum design, the reading style was either passive or interactive or combined with classroom group discussion model. From 18 weeks' observation, recording, semi-structured interview with children and parents, and children's work and file analysis, the results suggest that 1. Picture books are effective when children are actively involved; 2 . Children recognized with characters' positive dietary attitudes in picture books. 3. Children could clearly point out the similarities and differences between the roles' attitudes in the picture books and their own real life dietary attitudes. 4 . Children had ability in identifying with characters' positive dietary attitudes in picture books. 5. Facing peers in classroom showing negative response in verbal expressions, actions and emotions to healthy food, children could offer practical solutions for verbal communicating or body language to guide others to conduct appropriate and healthy dietary behaviors.
\end{abstract}

Keywords Picture Books, Children, Dietary Attitude, Early Childhood Education

\section{Introduction}

\subsection{Research Motivation and Background}

In preschool, many children do not eat enough fruit and vegetables (Geller \& Dzewaltowski, 2009[1]. For many reasons, from children's breakfast, lunch, and desert time, children tend to be unable to finish their meal, refuse to eat, cry and scream, unwilling to eat vegetables or throwing food away, all becoming the ordinary show on stage in the classroom. Chung Gang Memorial Hospital found in their clinical experiences that the prevalence of children aged $1-4$ 's food preference raises negative effect on children development significantly year by year, so correcting children's food preferring behavior should be highlighted as soon as possible (Alliance for a Healthier Generation,2011)[2] Also, for healthier weight in childhood (Tohill, 2005)[3] and adulthood (De Kroon et al, 2010/2011a/2011b/2012/2013; Droog et al, 2014)[4][5][6][7][8], healthy attitude toward fruit and vegetable is significantly important for children at young age(Kollataj et al, 2011; Heath et al, 2010/2011; Cotrufo et al, 2007; Sato et al, 2009; Yu et al, 2010)[9][11][12][13][14][15]. In addition, once food attitudes being developed during the preschool stage, such attitudes tend to extend into adulthood (Houston-Price, et al 2009; Kollataj et al, 2011; McGee, \& Schickedanz,2007) [16][17]. On the other hand, with research emphasizing on effect of picture books on children's language development (Whitehurst, 1988)[18] and recognition development (Zeinstra, Koelen, Kok, \& De Graaf, 2007)[19], an engaging way to stimulate children's fruit and vegetable consumption is exertion of shared reading, such as using picture books with characters modeling healthy food behaviors. Furthermore, among factors of school and family, teacher and parents have great impact on children's eating habits cultivation (Choi et al, 2008)[20]. In other words, children's negative attitudes towards or emotions for eating in school or at home are mainly resulted from eating preference that influences their health significantly. Good eating habits in childhood are likely for the children to maintain even when they are in adultery demonstrates the importance of children's eating attitude. Since picture books are what the children get in touch most often, the researcher decided to employ picture books for relative activity and teaching. For 
example, different situations and frameworks of the story can stimulate their thinking, induce them to imitate and identify good emotions and behaviors (Lin, 2010; Lin \& Lai, 2012)[21][22]. Therefore, the research intends to exert themed picture books integrated into preschool daily life activities and curriculum to elevate children's healthy eating attitudes, making eating become a kind of happy and enjoyable pleasure.

\subsection{Purposes}

The research issues are listed below:

1. How do young children perceive the roles' eating attitudes within the themed picture books

2. How do young children respond to the inter-relationship between the role's eating attitudes in the themed picture book and those of themselves.

3. After receiving the integrated curriculum and daily life activities of themed picture books, how do young children's eating attitudes change?

\subsection{Definition of Nouns}

(1) Negative eating attitudes: To show negative emotion expressions like resistant crying, or screaming, behaviors like refusal to eat, throwing food away, overturning the food, vomit, unwilling to eat, and so on.

(2) Positive eating attitudes: To show happy or calm emotions when eating, and willingness to try to eat food he/she dislike

\section{Literature Discussion}

\subsection{Basic Concepts of Picture Books}

Picture book recounts a story with rich images and text or even images more than text. Sometimes it involves what text cannot not express, and even substitutes the text, depending on images to "talk" about the story exclusively. Not all children's books with pictures can be called a picture book. Rather, only those with pictures and text delivering knowledge and influencing children through sense of vision can be called a picture book. Picture book is one which presents the content with images, and presents the plot of story with abundant visual messages (Tsai Ming-gin, 2010)[23]. In short, the researcher considered that picture book in the broad sense covers a wider range of books with images as the subject, and text as the subsidiary; so it is possible that the picture book are all images with unrestricted reading objects but without any text.

Characteristics of Picture Books can be defined as the following five types.

A. Children-based: Picture books' content should be concepts that can be understood by children, so the material, language, theme, and structure should all be directed to children's need and comprehension ability.

B. Artistic: Children are far more sensitive to color than the adult; color can not only affect children's interest in picture books, but also induce their different emotional reactions

C. Educational: A good story should carry "educational implication" rather than "educational purpose". In this sense, educational implication is hidden in the words and lines in the story for the readers to get enlightenment or retrospection

D. Delivery: Picture books achieve the effect of "words in pictures, and pictures in words" through textual narration in collaboration with image description. Picture books are not only message feedbacks but also mental implication and retrospection.

E. Fun: Picture books can be enjoyed, and reading picture books is accompanied with a sense of entertainment, which is why many picture books resort to manual operation and fun.

Functions of Picture Books could be categorized as the follows.

Picture books can enhance language learning ability, as Lin (2007)[24] considered that picture books can help children learn language, and the images in picture books serve as the bridge to link children with lingual vocabulary. Next, picture books can expand living experiences. Since there are a variety of story plot patterns of picture books; some make children situated in semi-reality and are connected with their old experiences to get assimilated or accustomed, while others offer children chances to expand different living experiences, even if they have not experienced before. Additionally, picture books help cultivate aesthetic literacy due to the delicately printed images and rich colors that make reading an extremely luxurious pleasure for children's sense of vision. A diversity of colors penetrate through the whole picture book, and, through reading, children can appreciate the images, and cultivate their aesthetic literacy. On the other hand, picture books can trigger imagination, for they are the primary source for the children to proceed creative thinking (Ma, 2010)[25]. Children can add their imagination and hope into picture books, and extend their imagination endlessly thereof. Furthermore, reading picture books can function as channels to release emotions accumulated in children's daily life without any causes nor explanations. Children must rely on an outlet-- reading is exactly the outlet for the kids to release those suppressed emotions (Chen, 2014; Chen \& Su, 2012)[26][27]. Finally, reading picture books can improve parent-child relationship. Whenever and wherever, pictures books are like a bridge for parent-child communication and interaction, so through parent-child shared reading, their interaction and relationship with parents will become even tighter.

Accordingly, picture books in this paper are composed by the characteristics mentioned above, including: 1. aesthetic literacy oriention; 2 . educational orientation; 3. 
Child-centered, suitable for children in different ages to be educated with adaptive development that can motivate them; 4. Fun-based: able to maintain and cultivate children's reading habits, and develop the ability of oral expression; 5 . To enhance children's emotions and social character development, promote parent-child interaction, and foster the harmonious air in the family.

\subsection{Picture Book Instruction with Children}

In the researcher's viewpoint, the main body of picture book teaching is story, where various kinds of teaching activities related to the theme of story are developed. In addition, it belongs to teaching methods to have children learn from teaching activities by storytelling, game playing, body performance, and so on.

A good picture book can expand children's horizon of life, provide emotional identification and releasing channels, develop a kind and caring heart, and cultivate writing skills and reading habits, so that children can enjoy reading (Chang, 2013)[28]. Therefore, selection of the picture books plays a crucial role. In addition, the picture book teaching process involves no fixed models nor methods, so the researcher consulted scholars' studies (Li, 2012; Lin, 2012; $\mathrm{Lu}, 2008 / 2013 ; \mathrm{Wu}, 2010)[29][30][31][32][33]$, and organized the main points regarding picture book teaching process.

Picture book teaching starts with good preparations, including selecting a proper picture book and arranging relative situation. The next step is regarding story-telling activities, such as stirring children's motivation, telling a story, and discussing the story. Before entering the thematic story, the teacher has to develop the atmosphere for children to listen to the story. Then, through language in coordination with pictures, the teacher tells the story that is not restricted by any standard models, so the children can understand the plot and have their imagination incited by the story. Upon finishing telling the story, teacher and children discuss and share their relative experiences, which allows children to practice thinking and organizing their thoughts, as well as expressing self-feelings orally. After story discussion, other relative teaching activities can be conducted to deepen children's comprehension of the picture book. Meanwhile, space should be provided to children to bring out their creativity and show their point-of-view and imagination of the story.

In short, the complete picture book teaching process can be classified into three stages--preparations before the reading activity, storytelling activity, and extended activities.

Hung's (2013) [34] research indicated that, around 440 years ago, there were educational thinkers compiling textbooks with pictures suitable for the psychological and cognitive development of the educated. Owing that reading is the root foundation of creativity, the neurotic mechanisms of both the psychological and cognitive development require ability to infer the whole from the single instance. In this aspect, reading serves as the quickest way to absorb knowledge, which can not only cultivate one's character, but also stimulate his/her brain (Agostoni, \& Brighenti, 2010; Go et al, 2013; Wang, 2007)[35][36][37]. "Father of Picture Boos". J. A. Comenius's (1592-1670) Orbis Senstualium Pictus proposed three educational functions for children, and set up children's picture books' position and value in education. UNESCO has set April 23 every year as the World Book \& Copyright Day.

\subsection{Children's Eating Attitudes}

\subsubsection{Relative Studies on Children's Eating Indicators}

Healthy eating and nutrition should be paid attention to since childhood, since other than unhealthy eating habits' negative influence on students' normal development, they may anticipate the chronic diseases in middle and old age (Moyer-Guse, \& Nabi, 2008/2010; Roberto et al, 2010)[38][39][40]. Based on the required daily nutrients in food, the food pyramid classifies food systematically. Additionally, the "National Eating Indicator" announced by Ministry of Health and Welfare (2011/2013)[41][42] lists 12 principles, including intake of Six Food Groups balance, calorie management, doing exercise for 30 minutes every day; breast milk nurture for at least 6 months, whole grain products as main food staple, food with less oil, sugar, and salt, less sugared drink, and more water; vegetables, reduced meat and processed food, moderate food and local food of the season, noticing source label, and moderate alcohol.

Results of Survey conducted by Children Welfare Foundation $(2010 ; 2014)[43][44]$ show that $50 \%$ of children do not take fresh fruit every day, and $40 \%$ of children do not eat vegetables every day. For children aged 4-6 and their care-givers, the results show that nearly $80 \%$ of children have the habit of drinking sugared beverages every day. It is found in research ( $\mathrm{Lu}$ et al, 2013)[32] that if children intake candies more than once and cookies more than thrice weekly, the occurrence rate of tooth decay increases subsequently. Besides, intake of snacks with high oil, high sugar, and high calorie will lead to Cranial nerves' losing controlling ability, and it will be likely to result in addiction of having snacks. Children's tendency to resisting against light foods when they have snacks with various favors by hand causes unbalanced nutrition. For children's overweight issue and their high demand of snacks in Taiwan, Ministry of Health and Ministry (2013)[42] has modified the regulations to control the advertisement amount and promotion methods by vendors of food improper for children's long-term intake.

\subsubsection{Exploration of Children's Eating Attitudes}

The psychological structure of attitude primarily involves three components: cognitive component, affective component, and behavioral component. Cognitive component includes related viewpoints, comprehension, and concepts. Affective component refers to individual's affective evaluation, like or dislike, and feelings, behavioral component means the individual's behavioral intention or 
inclination towards specific object. To conclude, attitude is the status of physiological and psychological preparation, and the specific inclination stirred when the individual faces specific object. Lastly, children's eating attitudes refer to children's physiological and psychological feelings and behaviors when they face specific food. In this aspect, Richard and Rhiannon considered that attitudes are composed by two potential positions, positive and negative tendencies (Jung et al, 2010; Yang, 2010)[45][46]. In accordance with demonstration of children's eating attitudes, "negative eating attitudes" and "positive eating attitudes" are briefly introduced as follows. The former relates to the individual's expression or feelings of dislike, resistance, hate, and so on in form of language, behaviors, or emotions when his/her faces certain food. The latter involves the individual's expression or feelings of like, acceptance, non-rejection, and so on in form of language, behaviors, or emotions whenhe/she faces certain foodr (Kim et al, 2008; Kim et al, 2011; Kim, \& Kim, 2010; Kim \& Choi, 2008; Son et al, 2009; Mani et al, 2010; Nyberg et al, 2011)[47][48][49][50][51][52][53] .

Frequently, formation of Children's Eating Attitudes is nurtured by the environment. Due to various kinds of factors, the individual generates different attitudes towards different objects in the living surrounding and experience. Attitude does not always remain the same; when the individual has new experience or cognition of certain object, he/she will change the original attitude. Formation of Children's Eating Attitudes includes A. Imitation and Learning: in regard of children's eating, the family's eating habits and food prepared by parents in daily time is the key to how preschool students choose their food. B. Influence of Children's Development: Children then currently are in the stage of growing permanent tooth, and it is difficult for them to chew vegetables and meat with more fibers, resulting in their negative impression on such food, and forming resistant attitudes in the long run. C. Children's Personal Factors: Taste sense is subjective personal perception, so how one accepts food varies. For example, food with strong favor or poor experience on specific food makes children hold negative attitudes towards them. D. Adult's Eating Education: To learn eating on their own is one of the tasks in childhood stage. Do not forbid the children nor intervene children's eating because of their coordination of eyes and hands. E. Change of Eating Patterns: Change in food patterns leads to children's failure in perceiving how invaluable food is, and thus creates the opportunity for them not to select food good to health, which is one of the reasons that form most children's negative eating attitudes.

\subsubsection{Change of Children's Eating Attitudes}

Attitudes are developed by the environment, so they are changeable, and characterized with stable property. The researcher consulted relative literature (Hoffmann, 1986; Ker, 2012)[56][57], and selected representative theories as follows:

From the perspective of Message Learning Theory proposed by Hovland and his colleagues, personal attitudes and other behaviors are learned from the environment and are thus changeable. Since mankind are reasonable and logic message dealer, their attitudes will change through new learning experiences.

For the Balance Theory proposed by Heider in 1958, it considers certain pressure that drives affection or evaluation exists in the system of cognition, and such relationship is called unit relationship, which mainly consists of similarity, closeness, and inter-belongingness.

Cognitive Dissonance Theory was proposed by the psychologist Festinger in 1957. According to the concept of Harmony Theory, cognition is divided into thinking, imagination, need, attitude, interest, ideal, faith, and etc, holding that when people's behavioral performance and existing attitudes are inconsistent, uncomfortable feelings will generate therein. To get rid of such feelings, people have to adjust their own attitudes to be consistent with their behavior. Social Judgment Theory proposed by Sherif and Hovland in 1961 relates to the individual's absorbing and assimilating new information on the basis of his/her own known or existing cognition and experiences. It indicates that when the individual encounters different perspectives or messages, he/she will judge which segment his/her attitude will fall upon, so that they can determine whether he/she will change the original attitude. As for Participant Changing Theory proposed by German psychologist Kurt Lewin, he argued that the individual's attitudes will change depending on the way he/she takes part in group activities, and the method that the individual employs in the group will both decide and change his/her attitudes.

There are rare theories related to change of children's eating attitudes; consequently, in accordance with basic concepts of "Attitude Change Theory" and referral to relative data, the researcher provided some methods for attitude change (Lin et al, 2012; Lee et al, 2011; Swanson et al, 2011)[22][58][59] . To start with Plan-based Procedures, to change the individual's attitude, the original attitude and position have to be understood to evaluate the distance between the existing attitude and the new one. Secondly, Chances for Participating Activities are increased through participating in activities, so people can touch more ideas and new perspectives different from the original attitudes as well as strengthening their feelings for specific issue or thing, all beneficial to change the attitude. Moreover, adults' modeling plays an important role, because children often imitate the adult's behaviors. Therefore, in daily life or during meal time, the attitudes towards food or behaviors involving eating courtesy are influential factors for how children accept and behave over food. Lastly, to develop children's good eating habits, people's daily behaviors will finally become a fixed model through continuous repetition or practice; that is, the so-called "habit" Based on the theories above, this study integrated them with picture book teaching to practice step by step in children's daily life activities in the preschool. 


\subsection{Relative Studies on Picture Book Teaching and Children's Eating Attitudes}

In the following section, research related to picture book teaching and children's attitudes are classified into "research on Picture Book Teaching and Attitudes" and "Evaluation Methods for Children's Attitudes Towards Picture Book Teaching" for further discussion. Research (Lin, 2012; Lu, 2008; Tsai, 2010)[30][31][23] show that picture book teaching has significantly positive influence. Additionally, Chen \& Su (2012)[26] employed picture book teaching to conduct research on influence of concept of death teaching on children's attitudes towards learning concept of death. The results show that children in the experimental group performed better in narrating concept of death and cognitive behaviors than those in the control group. Picture book teaching indeed has positive influence on each dimension of attitude, and it perceives that attitudes can be changed through methods. For methods to evaluate children's attitude, we can conduct observation, discussion, interaction, work presentation, and etc. in natural situation. Among them, the most convenient and easy assessment is teacher's or instructor's observation assessment.

Most preschools adopt teacher's or instructor's observation assessment. Since teacher is the one who understand the children the most, except parents, and he/she also understand assessment conducted before and after teaching the most (Chen \&Su 2012)[26], if the teacher and the instructor are the same person, not only there will be more observation time, but also assessment can be proceeded naturally without disturbing children's emotions.

As for methods for assessment, the teacher can understand children's attitudes through observing children's behaviors, activity development, and work collection in the thematic activity. Although this assessment method is easy and convenient, it may generate disturbance. Therefore, more relative information like "interview record", "object collection", "teacher's teaching review diary" must be collected for organization and cross-reference of data. Lin (2007) observed difference of eating habit performance of children in experimental group with guidance of picture books and children in control group without guidance of picture books. The questionnaire survey results show that the experimental group makes significant progress in behaviors related to healthy eating. $\mathrm{Wu}$ (2010) [33]designed picture book teaching programs with 20 Grade- 4 students as the subject, and the results show good effect of eating teaching with picture books. To integrate picture book teaching into eating activity and eating attitude, respectively, the results present positive influence and improvement, meaning that research on teaching through picture book tends to generate potentially positive outcomes.

\section{Research Methods}

The purpose of this research is to design a set of integrated daily activities based on children's eating topics as the theme. In addition, the qualitative research adopted thematic analysis by employing the concept of the integrative program in the food series of picture books for the children to recognize the correct eating, understand the healthy eating attitudes between themselves and the roles in the picture book, and identify with the correct eating attitudes. With the curriculum goal, the children are expected to guide other children to develop correct eating attitudes. During the research process, the researcher played the following two types of roles: A. The Complete Observer: Researcher does not take part in children's activity, but just observe the outside the activity. B. Participant is the Observer: Researcher takes part in teaching activity and proceeds observation at the same time. In regard of what he/she doubts, through natural interaction and interaction, he/she understands the children's idea.

Before starting the study, the researchers sent an agreement to the parents to authorize the teacher to conduct semi-structured interviews with the children after picture book teaching. After 18 weeks integrated curriculum design, the teacher followed to conduct semi-structured interviews with the children and patents. Through observation, interview, record, data collection, and children's work and file analysis, this research attempted to understand children's response to eating attitudes of the roles in picture books and their own change in eating attitudes. After collecting the data, the process of analyzing the data is inductive. The research adopted inductive reasoning where the premises are viewed as supplying strong evidence for the truth of the conclusion. During the research process, the following questions are considered: What are the children learning and doing during the picture books instruction? What are they trying to learn? How do children learn to recognize, identify and compare for the dietary attitude? What specific strategies are teacher used for motivating children interacting with picture books? How do young children discuss about and understand what is going on? What assumptions of dietary attitude are they building? The research work flow is as figure 1. 


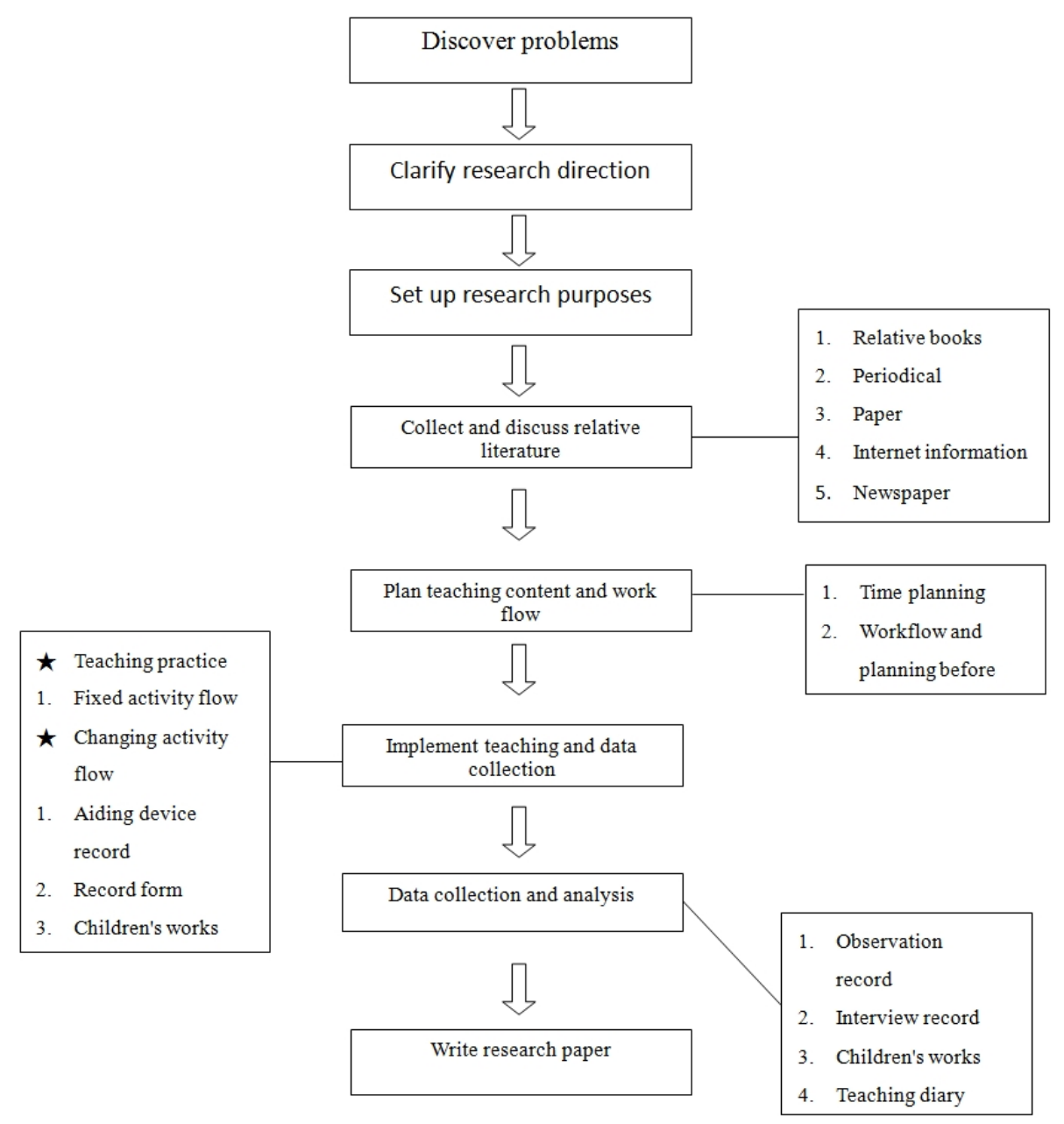

Figure 1. Research work flow

\subsection{Themed Picture Books}

The researcher invited 3 experienced early childhood educators to engage in book selection, and, as discussed in Literature Discussion in Chapter 2 with the following characteristics and selection of picture books collaborative with purpose of this research, the basic standard for selecting picture books was set up as follows:

(1) The picture books are related to children's eating habits, behaviors, attitudes, cognition.

(2) The story content allows the children to know and understand eating attitudes and perceive the importance.

(3) The story content delivers development of good eating attitudes that can enlighten the children.

(4) The story situation or content is close to children's daily life, so they are sympathetic with it and motivated to figure out how to solve the eating problems in the story or learn positive eating attitudes.

(5) Proper and aesthetic images, pictures, and overall design that can enrich children's sense of vision.

(6) The story content is active and fun so as to attract children to read it.

The following is a series of picture books about eating that try to make children recognize and identify with good and healthy food and encourage the peer to express opinions through oral and body language to help or remind other children establish good eating habits.

More than Age 2

1. Eating the Alphabet by Lois Ehlert. This beautifully illustrated alphabet book introduces kids to new fruits and vegetables

2. Growing Vegetable Soup by Lois Ehlert. Describes growing vegetables and using the vegetables to make vegetable soup. Growing Vegetable Soup includes a delicious vegetable soup recipe that can be made with veggies from your local farmers' market if you do not have time to grow all of the vegetables yourself

More than Age 3

3. Pancakes, Pancakes by Eric Carle. An entertaining tale to get kids thinking about where the ingredients in their foods come from. In Pancakes, Pancakes, a boy named Jack asks his mother to make him a pancake. Before Jack's mother can make a pancake, Jack must help her by threshing wheat, gathering eggs, churning butter, etc. 
4. I Will Never Not Ever Eat a Tomato by Lauren Child. My kids love Lauren Child's stories of siblings Charlie and Lola! In I Will Never Not Ever Eat a Tomato, Charlie tricks Lola into trying new foods by making up stories about each one. For example, Charlie tells Lola that the carrots he has served are orange twiglets from Jupiter. By the end of this story, Charlie and Lola are both having fun pretending to eat ocean nibbles (fish sticks), cloud fluff (mashed potatoes), orange twiglets (carrots), moonsquirters (tomatoes), and green drops

5. The Edible Pyramid: Good Eating Every Day by Loreen Leedy. Another favorite of my kids. While the USDA has recently ditched the food pyramid and replaced it with my plate, The Edible Pyramid remains a fantastic, kid-friendly introduction to the basic food groups and can be used to help encourage kids to eat a variety of foods.

6. Pizza at Sally's by Monica Wellington. Pizza is my favorite food to cook with kids, so I sought out a good picture book about pizza. Pizza at Sally's is written by Monica Wellington, whose colorful illustrations are always a hit with my kids. In Pizza at Sally's, Wellington simply introduces the ingredients needed to make pizza and describes how Sally makes a pizza. Please, share your favorite books about pizza in the comments below!

More than Age 4

7. Tops and Bottoms by Janet Stevens. A trickster tale with fantastic, Caldecott-worthy illustrations that teaches kids that we eat various parts of plants. For a meatier lesson about vegetables and plant parts, pair with The Vegetables We Eat by Gail Gibbons and let kids examine and taste various types of vegetables

8. Bread and Jam for Frances by Russell Hoban. I love all Frances books, and Bread and Jam for Frances is one of my favorites. In Bread and Jam for Frances, Frances initially turns up her nose at all food other than bread and jam. However, when her mother decides to serve Frances only bread and jam, Frances quickly misses eating a variety of foods. I absolutely love Hoban's descriptions of foods in this books as well as his both humorous and realistic portrayal of Frances' feelings

More than Age 5

9. Good Enough to Eat: A Kid's Guide to Food by Lizzy Rockwell. An introduction to nutrients and the digestive system for kids ages five through nine. My kids really enjoy Lizzy Rockwell's companion book about exercise: The Busy Body Book; the two could be read together. For more explicit encouragement for kids to eat healthy foods, see Eat Healthy, Feel Great by William Sears.

10. The Popcorn Book by Tomie de Paola. This book is chalk full of interesting information about popcorn.
The Popcorn Book depicts two friends making popcorn. While one friend makes popcorn, the other friend reads facts about popcorn from a book. Despite the lack of plot, Tomie de Paola's charming illustrations and the book's subject matter popcorn - are sure to appeal to a good number of kids.

\subsection{Research Field and Participants}

\section{Research Field}

The researchers selected teaching class from one of the researchers as the research field, which not only reduces the possibility that the research subject may feel uncomfortable due to proceed the research, but also raise the possibility that the subjects' natural behaviors may be observed.

\section{Introduction to the Preschool}

The researcher serves in the affiliated Preschool of the elementary school situated in Kaohsiung City. There are two classes, whole day class and half day class, both are mixed-aged classes. The elementary and kindergarten's nutritional lunch is trusted to an elementary school in Kaohsiung. The kindergarten's snack is arranged by edu-care giver to designate the qualified vendor to order and distribute.

\section{Class Condition}

The class taught by the researcher is whole-day class, with 12 kindergarteners, 5 boys and 7 girls; 14 pre-kindergarteners, 4 boys and 10 girls; and 4 preschools, 2 girls and 2 boys. There are a total of 30 students in the class.

\section{Research Participants}

The researcher found there were only four children's eating attitudes are positive, and the other 26 children showed different degree of negative reactions in lunch time in respect with language, behavior, and emotion.

\section{Research Coordinator}

The coordinator in this research is the co-teacher in the researcher's class with 34 years' teaching experience. In process of research, the coordinator mainly assisted picture book teaching activities, and video taking, picture taking, observation, and so on as well as feedback and suggestions.

\subsection{Data Collection and Analysis}

The data collection methods in this research include "observation record", "interview record", "object collection", and "teacher's teaching diary", as described below. (1) Before observation, get familiar with how to use record tools and check whether the functions are normal. (2) During observation, do not affect teaching activity. In addition to use pen and paper to record the keywords, effectively use record tools to assist video taking, recording, picture taking, and etc. to collect data. (3) After observation, record and supplement 
as soon as possible, and back up all data. Meanwhile, the observation record in this research was divided into two parts, "teaching observation" and "daily observation." Teaching observation was conducted for 40-50 minutes every Monday to Thursday for 12 weeks. The researcher employed assistant tools like recording, video taking, and picture taking to record data, and converted the recorded data into transcription as well as watching the video to observe children's explicit behaviors. In addition to teaching time, the teacher also recorded whenever she noticed children engaging in any eating related activities. Considering interview record, the purpose of interview is to understand the subjects' thought, and respect their interpretation of their own behaviors (Lin Hsiu-hui, 2012)[30]. The interview record in this research mainly aimed at supplementing data of then current problems or doubts unable to be explored in process of subjects' proceeding activities. In addition, information unable to obtain from many interviews and interviews can be extracted. This research collected objects in the research process to raise the validity. Concerning Teacher's Teaching Diary, after each class, the teacher conducted retrospection record in respect with the teaching content and children's reaction.

\subsection{Research Reliability}

In qualitative research, the researcher's subjective involvement is unavoidable; therefore, the researcher must adopt various kinds of methods to verify the collected data. By means of the following approaches, "long-time observation", "data triangulation", and "peer verification" were employed to raise the validity of this research. Concerning Long-time Observation for 18 weeks, the researcher is the teacher of the class in this research, so her observation time was 8:00 am to $16: 00 \mathrm{pm}$ from Monday to Friday for 18 weeks. For Data Triangulation, this research mainly adopted data triangulation via observation record, case interview, group discussion, written/drawing works, teacher's teaching diary, and several written documents to proceed data analysis. For Peer Verification, the researcher invited two peers to proceed data verification. The first one is the coordinator in this research as well as the co-teacher of the researcher. The other is the educare giver in the kindergarten where the researcher works. Both work in the kindergarten, so the research's objectivity and reliability can be enhanced.

In addition, the researcher used observation record, interview record, pictures, learning sheet, and children's creative works for data analysis and proposal of concrete evidences to illustrate the results of the research. Based on research ethics, and under the premise of the subjects' mental and physical condition, willingness, and interest, the whole research process has been conducted in considerations.

\section{Discussion}

\subsection{Children's Understanding of the Eating Attitudes of the Role in the Picture Books}

The understanding in this paper refers to the interpretation for the eating attitudes of the role after children read the picture book. As for interpretation, it signifies a kind of sympathetic feeling for the content generated by the reader in process of reading the picture book, and the reader can describe the deep thought and feeling in his/her mind by words concretely.

\subsection{Distinguish of the Positive and Negative Eating Attitudes of the Role}

Children's distinguishment of the positive or negative attitudes of the role in the picture book is mainly based on the role's verbal reaction, behavioral performance, and the influence of the role. The research results show that in aspect of language dimension, children would judge the food is positive or negative according to the kind of food the role faces and his/her responding method, while in aspect of behavioral dimension, children judge the role's eating attitudes on seeing his/her eating attitudes. In regard of the influence dimension, it generally refers to children's cognition of the role's eating process in the story that causes their or others' negative emotions like happy or unhappy, or angry.

To sum up, children's judgment on the role's positive and negative attitudes in the picture book is primarily according to the food's type and their behavioral attitudes. Food can be classified into healthy and unhealthy food; therefore, in process of eating, when the role expresses negative words, behaviors, or emotions such as he/she does not want to eat, reject to eat healthy food, and cries or screams, those expressions are considered as negative eating attitudes. Additionally, when the role shows that he/she wants to eat the unhealthy food or eat too much unhealthy food that would influence health, such are also negative eating attitudes. That is to say, children's understanding of the role's eating attitudes are formed by specific foundation, and it is fair on the other hand.

\subsection{Comparison of Children's and Role in the Picture Book's Response to their own Eating Attitudes}

\subsubsection{Children's response to their own eating attitudes}

By means of discussion on picture book teaching, interviews, and observation record at lunch, the researcher understand children's reaction to their own eating attitudes, including

(1). Aware of their bias for food

(2). Unaware of their own bias for food

\subsubsection{Compare Children's Response to Their Own and the Role's' Eating Attitudes}

(1). The children know the role's negative eating attitudes are not good and therefore modify their own. 
(2). The children know the role's negative eating attitudes are not good but remain the same

(3). The children know the role's positive eating attitudes are good and therefore modify their own.

(4). The children know the role's positive eating attitudes are good but remain the same.

In short, children are clear about the role's positive and negative eating attitudes, and can realize the good and bad influence of positive and negative eating attitudes. Nevertheless, the interval between knowing and doing differs personally; some children are alert and retrospective with help of the role's example, but others remain unchanged.

\subsubsection{Methods and Applications for the Role Proposed by Children}

In group discussion, children can pick up the role's negative attitudes one by one, and proposed various solutions to the problems the role encounters. Additionally, when the role's negative attitudes are the same with the children's, the solutions proposed by children will be applied to themselves mostly.

(1). With application to their own eating attitudes: For the role's bias for food and improper eating behaviors, children have proposed many methods for improvement. Some children would apply their proposal to eating, and eat up all food smoothly, achieving modification of their own eating.

(2). Without application to their own eating attitudes: It can be understood from group discussion that children were clear about positive and negative eating attitudes and the influence of those attitudes on their body. In addition, when the issue comes back to the children, it can be found that most children are influenced by the role in the picture book. They would adjust eating attitudes actively, which demonstrates the unelectable influence of picture books on children.

\subsection{How children's Eating Attitudes Change Before and After Picture Book Teaching}

\subsubsection{Change in Language Dimension}

In the prior period of the research, children's performance in language dimension was very direct and intense. As picture book teaching proceeded, the researcher found that children's negative language towards food became less and less gradually. In the later period, not only the negative reactions decreased, but also they used the content of picture book teaching to expressing the positive response to food. At the end of this research, most children in the class did not perform negative language response at all.

\subsubsection{Change in Behavioral Dimension}

In the research process, the researcher designed a lot of relative activities for children to participate in person. For example, making pumpkin cookies could raise children's participation rate and enhance their acceptance degree for food. In comparison to the prior research period when children's eating attitudes tended to be negative, as it entered the later period, they seldom showed bias to specific dishes, and the number of those who selected their preferred dishes declined gradually. Moreover, by means of varied methods, children raised their acceptance degree for food, and were willing to accept and challenge eating what they did not like, proving children's eating dimension has undergone positive changes.

\subsubsection{Change in Emotional Dimension}

When children face food, the reactions like joy, anger, sadness, and pleasure they show are all presentationsof emotional dimension of the eating attitudes (Guo et al, 2012)[60]. Prior Period of Research, through observation, the researcher found that there were less children that showed negative emotional dimension of the eating attitudes in her class. When facing what they did not want to eat, those children showed obvious depression and crying in addition to negative verbal and behavioral reactions, and some even refused to go to school. Besides, from learning sheet and interviews, it is learned that most children in class had bad mood because of meal or desert they did not like, particularly vegetables. In Later Period of Research, children's emotional reactions became less intense, and the frequency was less as well. In addition, when children faced what they did not like to eat, their showed positive emotions after trying to eat:--negative emotions lessen apparently, and they expressed more positive eating emotions

In the prior period of research, more than half of the children drew an unhappy or crying face in "diary of my mood" at lunch to show they were not happy during lunch time. However, in the end of the research activity, the researcher asked the children to think about the scene at lunch and drew "my lunch time". By means of interviews, she understood the children's mood in eating lunch in the kindergarten after picture book teaching class. In the drawing of "lunch time", they drew different details, including themselves and their good friends. However, the researcher noticed that on all figures drawn by the kids, there was always a big smile. After the interviews, children all felt they were happy during lunch time, not just because of accompany of their good friends, but also because they became daring to eat vegetables, and even ate up all the meal. In "my lunch time", the children in the whole class drew people with a smile. They were happy with trying to eat what they dared not before, and often shared their happiness with the researcher.

In later period of research, several children who only eat their preferred food made great progress. Interestingly, when they were eating the unfavorable food, they would come up to the researcher, opened their mouth, and showed what was in their mouth happily. At the same time, seeing such condition, other children followed to have the researcher watch the food in their mouth and the bowl, making the researcher could not help but keep on praising. However, the atmosphere at lunch in class became very agreeable. 


\subsubsection{Change as a Whole}

At the end of this research, the researcher designed "club pizza" making as the conclusive activity for picture book instruction integrated into this research in preschool. In the process, the researcher proceeded the activity from introduction of the required materials, instruction of how to select materials for the children, to eating pizza, and observing children's performance in eating attitudes involving language, behaviors, and emotions. Also, the researcher devoted herself into collecting children's changes in eating attitudes at home, so she asked parents to help fill out the form of "Eating Attitudes Survey" in order to further understand the extent of children's change in eating attitudes, which she is going to describe in the "School--Conclusions of Picture Book Teaching" and "Parents' Feedback" as below:

\section{(1). School--Conclusions of Picture Book Teaching}

The research shows children's positive progress in selecting eating foods within the picture books instruction. Take it for example, while in the later period of the research, the researcher prepared vegetables that most children originally hate-- green peppers, onions, and red carrot; however, the children not only showed no negative reactions, but also rushed to speak the name of food and the nutrition each food contains loudly, "That is little red genie, and there is a green genie inside!" Even when they saw green peppers, they did not behave as they used to say something negative, "I don't want to eat that ugly stuff", showing that children's language dimension in eating attitudes is positive.

Before making pizza, the researcher described the procedures, while she encouraged the children to be courageous to try. In process of cooking, the ingredients were decided by the children themselves without the researcher's interference. Most children added all ingredients with moderate amount. In addition, they would apply to the content in the previous activities, such as: "It is healthy for you to eat all dishes, and the little genie will appear only when you eat everything". Although there were some children who disliked certain dishes, they just kept that in mind and reduced the amount to eat. With respect to having club pizza, all children ate up all pizza smoothly, and no one picked up what they dislike nor did they hide or throw away the food. In addition, children love the picture books and love the food they eat every day. The researcher found out that the children wore a smile until the end of the activity. Perhaps it was due to the interesting activities children involve for nutritious food, or maybe it was because of fun in making pizza collaboratively in preschool; anyway, seeing the children's negative attitudes in respect with language, behaviors, and emotions decreased and their positive attitudes increased in the end of the activity, the researcher felt so much gratified.

\section{(2) Parents' Feedback}

In the beginning, although the researcher did not demand parents to coordinate by adjusting child's eating attitudes with considerations on their painstaking and love for the child, at the end of the activity, the researcher saw the child make progress in many aspects, she would like to understand how the child did at home, and thus issued "Eating Attitude Survey" for parents to fill out. A total of 11 parents stated that children could eat up green peppers, vegetables, carrots, and meat; 13 parents signified that children had learned to try eating, and four said that children were still unwilling to eat unfavorable foods. Questions are elaborated as follows.

Question 1: "What would the kid do when he/she sees unfavorable food? Has he/she improved?"

Two parents expressed that the children have never had bias for food, so they do not behave particularly. As for the other children, the parents signified that they would cry, grouch, throw the food away, lose temper, or ask grandma/other family member to eat. In regard of response to improvement, four parents felt the children make a little improvement, and two thought they do not improve.

Question 2: "How much does the kid eat now--standard, more, or unchanged?"

A total of 25 parents showed that the children could eat up the standard amount of food, while 3 parents felt the children eat more than they used to be.

Question 3: "How often does the child demand to buy junk food? Less often? or unchanged?"

More than half of the parents indicated that the children's demand and intake amount for junk food have decreased, and the remaining ones felt the children just ate slightly less than they used to do.

Question 4: "Describe how the child has their meal at home"

All children would refer to the little genie in the food when they are having a meal. C26's mother described, "Every time when C26 is eating vegetables, he would say 'having vegetables summons genies!"' There are 6 children will say something to reject the junk food when they see it. As C1's mother expressed, "If Brother wants to eat junk food, C1 will tell him not to!" Moreover, what appeared in the teaching activities also take place on the dining table at home, as C28's dad depicted, "C28 is always asking what kinds of food are healthy, and what kinds of food are unhealthy. Is there superman of health? Is my bowel movement smooth or not?" Also, C2's mother showed, "C2 did not like to eat tomatoes in the past, but he eat little bite by bite now, he said that only by this way will the healthy little superman live in his belly and so on".

From making club pizza, it can be learned that at the end of picture book activity, children's eating attitudes differed significantly from those in the beginning of the semester and those in prior period of the research in regard of reduction of negative reactions and conversion from negative to positive dimensions of language, behaviors, and emotions. As for the feedback from parents, it can also be observed that most children's eating attitudes have converted to positive ones. Consequently, it is evident that children have taken rooted change in eating attitudes, not just showing those attitudes 
for the teacher nor merely affected by the peers.

In this section, we have learned that children's performance in various dimensions involving eating attitudes have changed from negative to positive gradually. It is true that not all activities can lead to their change or positive influence, but it can also be found from the observation record that each child has obtained positive change to different degrees in different dimensions involving eating attitudes. Particularly, in later period in the picture book teaching activity, with accumulation of experiences in picture books and various activities, a tendency of healthy and balanced diet lingered in class. Certainly, few children still stuck to their own eating style, but their progress and change were also seen by the researcher. Every step is a great progress in the researcher's eyes.

Above all, picture book teaching indeed has multi-dimensional influence on children's eating attitudes. On the basis of discussion targeting at the eating attitudes of the role in the picture book, it can be understood that children's indicator of the positive or negative eating attitudes is the same with the adult's, but some children can further learn a lesson from the role's eating attitudes by means of adjusting their own.

In addition, in the prior and later period of this research, it can be sensed severely the positive change of children's eating attitudes in respect with language, behaviors, and emotions. Unconsciously the eating knowledge and concepts are transformed to personal habits, which even take root as eating attitudes at home. According to literature discussion, picture book teaching has multi-dimensional positive influence on children, but in this research, it is not only restricted to instilling knowledge of eating education, but involves planning programs and implementing various patterns of activities so as to trigger children's learning motivation and intention ( $\mathrm{Lu}$ et al, 2008). Therefore, the researcher designed diverse teaching activities, and made teaching tools by her own to simplify the complicated concept to raise children's participation in activities as well as passion in joining in activities in corner time, outdoor time, and meal time.

Although parents' eating cultivation methods and eating attitudes are the important factors to form children's eating behaviors and habits, when it comes to strategies on improving knowledge of food nutrition, eating attitudes and behaviors, school as where promotes nutrition education has become the approach adopted most frequently, and it can certainly raise students' nutrition knowledge. In this research, the field is limited to campus life, but effective picture book teaching permits the children to absorb relative knowledge, and further modify their own eating attitudes, while extending it into family life. Also, as suggested in (Cheng, 2012; Chen, 2010; Lautenschlager, \& Smith, 2007; Ritchie et al, 2010) [61][62][63][64]study, if preschool can put more stress on eating guidance (Mohd et al, 2008; Choi, 2010)[65][66], effect of children's nutrition education will be fostered to a large extent. Above all, children's eating attitudes are not only the family's or the school's obligation, if both parties can communicate, coordinate, and cooperate with each other, it will certainly establish the most healthy life and environment for children.

\section{Recommendations and Suggestions}

\subsection{Recommendations}

Observations by the researcher revealed that children in the interactive sessions of storybooks activities were more involved and progressively active during the reading sessions than the children in the passive sessions with independent reading. For example, when children listened attentively to the storyteller, they would always raise their hands when a question was asked, and they would like to loudly verbalized the correct answers, especially when they are singing along enthusiastically with the food themed songs incorporated into the story and demonstrated modeling behavior (e.g., the story character's 'fit and strong' pose).The research revealed "how children perceive the role's eating attitudes in the picture book" and "how children respond to relationship between eating attitudes of the role in the picture book and that of themselves". In addition, after picture book teaching, the teacher led the children to think about how the children's eating attitudes changed, and the results showed that children recognized the picture book roles' positive dietary attitudes in picture book, and children could clearly point out the similarities and differences between the picture book roles' attitudes and their dietary attitudes in real life. Moreover, children had ability of identifying with the roles' positive dietary attitudes in picture books. When children's peers in the classroom showed negative response with verbal expressions, actions and emotions to healthy food, children could offer practical solutions for verbal communication or body language to guide others to behave appropriately and eat healthily.

\section{Children's Understanding of Eating Attitudes of the Role in the Picture Book}

As far as unhealthy foods that damage children's constitution is concerned, they recognized that it was negative dietary attitude, so they could offer solutions to adjust it. Most children thus knew clearly that they were picky eaters, but a few of them were picky in reality even though they are not aware of it. In addition, children could clearly describe the disadvantages and effects of the roles' positive and negative dietary attitudes, among which some would adjust their own attitudes while others wouldn't. To make a step further, children could propose solutions to the characters' negative dietary attitudes, and most of them would apply them to their own attitudes while a few of them wouldn't. At last, regarding the change of children's dietary attitudes after picture book teaching, a lot of children clearly showed much less negative verbal expressions like "I don't want to eat, I won't eat". Instead, a majority of children had positive verbal attitude, and showed much less actions to 
refuse to eat or hide food, which signifies positive attitude changes in action level. No children became anxious or cried and screamed because of food, showing positive attitude change in emotion.

\section{Children recognized with the roles'positive dietary attitudes in picture book.}

From group discussion, interviews, learning sheet, and integrated thematic activities, it is learned that children's comprehension of the role's eating attitudes depended on evaluating the roles' eating attitudes from the three dimensions-- language, behaviors, and influence when they were having a meal. When the roles faced healthy food, children's language and behaviors would show approval, or they would be influenced positively. For example, children's body became healthier, the bad bacteria were defeated, and they refused to eating unhealthy food. All the mentioned reactions were regarded by the children as positive eating attitudes. Above all, children's comprehension of the roles' eating attitudes was decided by the role's performance.

\section{Compare Eating Attitudes of the Children with the Role in the Picture Book}

Children could clearly point out the similarities and differences between the picture books characters' attitudes and their own real life dietary attitudes. Most children understood their own eating attitudes, and they could clearly distinguish the role's positive and negative eating attitudes. In the meantime, in group discussion, children expressed their intention to learn positive attitudes and helped the role to figure out various methods to improve negative eating attitudes. When the role's eating attitudes are similar to the children's, most of them adopted the methods proposed in group discussion, such as cutting into pieces, eating small bites, and eating with rice. They would improve and adjust diet, and raise their acceptance for food. As for unhealthy food, half of the children were also influenced by the role to actively reduce the amount of food. Nevertheless, even though few children could propose solutions to the role's negative eating attitudes, they failed to apply the solutions to themselves, and thus remained the then current condition. For example, on seeing unfavorable food, they still showed verbal rejection Although children might be willing to try, they could not finish eating up the food. Particularly, after understanding the negative influence of unhealthy food through the role, half of the children could not resist against junk food.

\section{Children's change in eating attitudes before and after picture book teaching}

Children could identify with characters' positive dietary attitudes in picture books. Upon facing peers in the classroom who showed negative response in verbal expressions, actions and emotions to healthy food, children could be able to offer practical solutions by verbal communication or body language to guide the peers to conduct appropriate healthy dietary behaviors.

Before observation period and picture book teaching, most children's language, behaviors, and emotions of eating attitudes were negative. For example, they rejected the food they did not like upon seeing it; picked up the unfavorable food and threw it away; cried and grouched for they did not want to eat. All were verbal refusal, refusing behaviors, and bad emotions. However, in later part of picture book teaching, although not all children showed positive eating attitudes, most children's negative eating attitudes in language, emotions, and behaviors reduced, and even disappeared. All had positive changes in different stages and levels. It is found from observation that in regard of eating attitudes, most children showed positive change and good reaction. For example, the children presented positive reaction to unfavorable food-- they asked for trying the food actively, made use of methods to improve their acceptance of the food, and improved their emotions. On the other hand, most children transformed the eating knowledge and concepts into eating habits, and melted the adjusted eating attitudes into family life, which demonstrated the positive impact of picture book teaching on children's eating attitudes.

\subsection{Research Suggestions}

\section{Pay attention to order of picture book teaching}

In order to draw the children's attention, the order of picture book teaching took what was similar to children's living experience as the priority. It successfully arouses their attention, but the researcher also found that children's concepts of eating health are not solid nor sound. Therefore, in discussion of the first three picture books, it was hard to output practical solutions. In this regard, it is suggested that if teachers are interested in this subject, they can start teaching by picture books with more "concept of health" to accumulated correct eating concepts, which may produce different effectiveness.

\section{Group discussion should not take too long time}

After picture book sharing, the researcher would proceed group discussion that focused on the role in the story. In order to understand children's opinions and feelings for the role, the researcher had prepared a lot of questions. However, she found that children's concentrative power weakened gradually, and then it became difficult to conduct group discussion. Since group discussion is individual oriented and tend to be static, so it is difficult to arouse interest or sympathy of the whole class. Consequently, it is suggested to divide the questions in group discussion into several parts, so that children's interest may be maintained.

\section{Make good use of parent-child cooperation}

It is no doubt that eating plays an important role for children. However, most parents cannot insist their eating education for children due to love and pampering. At this 
point, it can be understood from conclusions that picture book teaching has positive improvement in children's eating attitudes. It can even be observed from parents' feedback sheet that children's eating attitudes have made a progress at home, while some parents even show extreme agreement with such teaching activities. So, the researcher suggests that by inviting parents to have long-term collaboration with the teacher, so that parent-teacher cooperation can be achieved. Under such dual implementation by the teacher in school and the parents at home, it will be effective and make progress in respect with children's eating attitudes.

\section{Lengthen the research time}

From the data in the later period of this research, it can be observed that most children's eating attitudes have positively changed. More importantly, they took those positive eating attitudes into family, making family members agree with such teaching activities. Unfortunately, when the research ends, will those changes continue to affect children's eating attitudes--it needs subsequent observation to follow. It is therefore suggested that researchers in the future increase research time to observe the condition children's eating attitudes when there is no teaching stimulation. Also, the results can be observed as analysis of the influential factors to serve as constructive recommendations for research in the future.

\section{REFERENCES}

[1] K. S. Geller, \& D. A. Dzewaltowski. Longitudinal and cross-sectional influences on youth fruit and vegetable consumption. Nutrition Reviews, Vol. 67, No. 2, 65-76, 2009.

[2] Alliance for a Healthier Generation. Eating healthy, growing strong [Campaign website]. http://www.healthiergeneration. org/parents, 2011.

[3] B. C. Tohill. Dietary intake of fruit and vegetables and management of body weight. Geneva, Switzerland: World Health Organization, 2005.

[4] M. L. De Kroon, C. M. Renders, J. P. Van Wouwe, S. Van Buuren, \& R. A. Hirasing. The Terneuzen birth cohort: BMI changes between 2 and 6 years correlate strongest with adult overweight. PLoS One, Vol. 5, No. 2, e9155, 2010.

[5] S. M. De Droog, M. Buijzen, S. J. Opree, \& P. M. Valkenburg. The appeal of congruence between brand characters and products. Uncovering the affective mechanisms leading to product choice. In Paper presented at the annual meeting of the International Communication Association, Boston, MA, 2011.

[6] S. M. De Droog, P. M. Valkenburg, \& M. Buijzen. Using brand characters to promote young children's liking of and purchase requests for fruit. Journal of Health Communication, Vol. 16, 79 - 89, 2011.

[7] S. M. De Droog, M. Buijzen, \& P. M. Valkenburg. Use a rabbit or a rhino to sell a carrot? The effect of character- product congruence on children' s liking of healthy foods. Journal of Health Communication, Vol. 17, 1068 - 1080, 2012.

[8] S. M. De Droog. Establishing and explaining the impact of characters on young children' s healthy food choices (Doctoral dissertation). http://dare.uva.nl/record/445573, 2013

[9] S. M. Droog, M. Buijzen, \& P. M. Valkenburg. Enghancing children's vegetable consumption using vegetable-promoting picture books. The impact of interactive shared reading and character-product congruence. Apppetite, Vol. 73, 73-80, 2014.

[10] W. Kollataj, K. Sygit, M. Sygit, I. D. Karwat, \& B. Kollataj. Eating habits of children and adolescents from rural regions depending on gender, education, and economic status of parents. Annals of Agricultural and Environmental Medicine, Vol. 18, No. 2, 2011.

[11] P. Heath, C. Houston-Price, \& O. B. Kennedy. Increasing food familiarity without the tears. A role for visual exposure? Appetite, Vol. 57, 832-838, 2011.

[12] P. Heath, C. Houston-Price, \& O. B. Kennedy. Can visual exposure impact on children's visual preferences for fruit and vegetables? Proceedings of the Nutrition Society, 69(OCE6), E422. doi: 10.1017/S0029665110002855, 2010.

[13] P. Cotrufo, S. Cella, F. Cremato, \& A. G. Labella. Eating disorder attitude and abnormal eating behaviours in a sample of 11-13-year-old school children: The role of pubertal body transformation. Eating and Weight Disorders-Studies on Anorexia, Bulimia and Obesity, Vol. 12, No. 4, 154-160, 2007.

[14] Y. Sato, A. Yamagishi, Y. Hashimoto, N. Virgona, Y. Hoshiyama, \& K. Umegaki. Use of dietary supplements among preschool children in Japan. Journal of nutritional science and vitaminology, Vol. 55, No. 4, 317-325, 2009.

[15] O. K. Yu, Y. K. Rhee, H. S. Sohn, \& Y. S. Cha. Effects of nutrition education on overweight and obese children in Chonbuk area-Focus on food habit, eating behaviors, dietary attitude, nutrition knowledge and nutrients intake. Journal of The Korean Society of Food Science and Nutrition, 2010.

[16] C. Houston-Price, L. Butler, \& P. Shiba. Visual exposure impacts on toddlers willingness to taste fruits and vegetables. Appetite, Vol. 53, 450 - 453, 2009.

[17] L. M. McGee, \& J. A. Schickedanz. Repeated interactive read-alouds in preschool and kindergarten. The Reading Teacher, Vol. 60, No. 8, 742-751, 2007.

[18] G. J. Whitehurst, F. L. Falco, C. J. Lonigan, J. E. Fischel, B. D. DeBaryshe, M. C. Valdez-Menchaca, \& M. Caulfield. Accelerating language developmentthrough picture book reading. Developmental Psychology, Vol. 24, No. 4, 552 $559,1988$.

[19] G. G. Zeinstra, M. A. Koelen, F. J. Kok, \& C. De Graaf. Cognitive development and children' $s$ perceptions of fruit and vegetables. A qualitative study. International Journal of Behavioral Nutrition and Physical Activity, Vol. 4, 30, 2007.

[20] E. S. Choi, N. R. Shin, E. I. Jung, H. R. Park, H. M. Lee, \& K. H. Song. A study on nutrition knowledge and dietary behavior of elementary school children in Seoul. Nutrition research and practice, Vol. 2, No. 4, 308-316, 2008. 
[21] Lin Fang-jing. Influence of Picture Book Recounting and Discussion of Children's Prosocial Moral Deduction; Journal of National Taichung University: Education, Vol. 24, No. 1, 107-127, 2010.

[22] Y. C. Lin, \& T. J. Lai. Research on the Effect of Integration of Picture Books into Reading Teaching on Children's Reading Motivation; Early Childhood Education, Vol. 307, 28-48, 2012.

[23] M. J. Tsai. Exploration into Picture Book and the Teaching, compiled by Huang Wen-shu, Practice and Philosophy on Picture Book Teaching in Kindergarten; 23-50, Taipei, Show-we Information Co., Ltd, 2010.

[24] W. Lin, H. Yang, C. Hang, \& W. Pan. Nutrition knowledge, attitude, and behavior of Taiwanese elementary school children. Asia Pacific journal of clinical nutrition, Vol. 16, 534, 2007.

[25] H. C. Ma. Action Research on Exertion of Drawings in Picture Books to Guide the Children's Creation of Drawing; Department of Early Childhood Education, National Pingtung University, unpublished Master Thesis, Pingtung City, 2010.

[26] B. C. Chen, \& C. H. Su. The Influence of Employing Picture Books to Proceed Concept of Death Teaching on Children's Learning Attitudes towards Concept of Death, Children Care and Education, Vol. 2, 23-46, 2012.

[27] M. Y. Chen. Action Research on Picture Book Teaching's Enhancement of Children's Reading Ability; Department of Education, National Taipei Education University, unpublished Master Thesis, Taipei City, 2014.

[28] S. Y. Chang. Exploration into Effect of Picture Book Teaching on Raising Children's Prosocial Behaviors; Department of Early Childhood Care and Education, Shu Te University, Kaohsiung City, 2013.

[29] H. M. Li. Application of Positive Psychology to School Education; Kaohsiung, Liwen, 2012.

[30] H. H. Lin. Research m Kindergarten Teachers' Story Iteration Teaching; Education Institute in Chiayi University, unpublished PhD Thesis; Chiayi City, 2012.

[31] M. K. Lu, \& M. Y. Kuo. To Weave Children's Life--Kindergarten's Employment of Picture Book Teaching; Taiwan Education, 2-9, 2008.

[32] L. C. Lu, Y. J. Yang, H. W. Yiu. Long-term tracking Preschool Children aged 2-5's Intake of cakes and deserts and refined sugar; Taiwan Public Health Journal, Vol. 4, 346-357, 2013.

[33] S. H. Wu. Research on Picture Book Teaching's Influence on Children's Self-concept and Peer Interaction; unpublished Master Thesis, Department of Early Childhood Care and Education, Shu Te University, Kaohsiung City, 2010.

[34] L. Hung. Let the Child Find the Key to Open the Door of Knowledge; CommonWealth Magazine, October 16; from http://www.cw.com.tw/article/article.action?id=5053012, 2013.

[35] C. Agostoni, \& F. Brighenti. Dietary choices for breakfast in children and adolescents. Critical reviews in food science and nutrition, Vol. 50, No. 2, 120-128, 2010.
[36] Y. S. Go, E, R, Jeon, \& L. H. Jung. The dietary habits and perception of vegetable intake of elementary students in Gwangju and Jeonnam. Journal of the Korean Society of Food Science and Nutrition, Vol. 42, No. 2, 223-233, 2013.

[37] J. G. Wang., M. C. Cui, \& A. F. Su. Study of Nutritional Knowledge-Attitude-Dietary Behaviors in Children With Simple Obesity [J]. Medical Recapitulate, Vol. 17, 037, 2007.

[38] E. Moyer-Guse. Toward a theory of entertainment persuasion. Explaining the persuasive effects of entertainment-education messages. Communication Theory, Vol. 18, 407-425, 2008.

[39] E. Moyer-Guse, \& R. L. Nabi. Explaining the effects of narrative in an entertainment television program. Overcoming resistance to persuasion. Human Communicatio n Research, Vol. 36, 26-52, 2010.

[40] C. A. Roberto, J. Baik, J. L. Harris, \& K. D. Brownell, K. D. Influence of licensed characters on children's taste and snack preferences. Pediatrics, Vol. 126, 88-93, 2010.

[41] Ministry of Health and Welfare. Announcement of new "National's Eating Indicator" and "Daily Eating Guide", Taipei: Ministry of Health and Welfare, July 6, 2011, quoted from http://heaith99.hpa.gov.tw/Hot News/h_NewsDetailN. aspx?TopIcNo=6257, 2011.

[42] Ministry of Health and Welfare. Suggested Value of Body Mass Index for Children and Youngsters; Taipei, Ministry of Health and Welfare; June 11, 2013; Quoted from http:// www.pediatr.org.tw/ DB/News/file/1726-1.pdf, 2013.

[43] Child Welfare League Foundation. 2010 Report on Survey of Taiwan Children's Bias for Food; August 23, 2010, quoted from http://www.children.org.tw/news/advocacy_detail/313, 2010 .

[44] Child Welfare League Foundation. Children Nurtured by Junk Food; April 12, 2014, from http://www.children.org.tw/ news/advocacy_detail/1184, 2014.

[45] H. R. Jung, M. J. Lee, K. C. Kim, J. B. Kim, D. H. Kim, S. H. Kang, ... \& Y. B. Park. Survey on the sodium contents of nursery school meals in Gyeonggi-do. Journal of the Korean Society of Food Science and Nutrition, Vol. 39, No. 4, 526-534, 2010.

[46] J. H. Yang. The effectiveness of after-school progaram in practical arts education on the change of disabled children toward dietary attitude. J Elementary Educ, Vol. 23, No. 1, 163-182, 2010.

[47] S. B. Kim, \& H. J. Choi. Effects of nutrition education using food exchange system: changes in elementary students' nutrition knowledge, dietary attitude and nutrients intake. Korean Journal of Community Nutrition, Vol. 13, No. 6, 922-933, 2008.

[48] B. R. Kim, \& Y. S. Kim. Dietary behaviors, body satisfaction and factors affecting the weight control interest according to gender of middle school students in Wonju area. Journal of the Korean Society of Food Science and Nutrition, Vol. 39, No. 9, 1295-1304, 2010.

[49] B. H. Kim, M.Y. Sung, \& Y. Lee. Comparison of the nutrient intakes by the score of dietary action guides for Korean children among the elementary school students in Gwangju city. Korean Journal of Community Nutrition, Vol. 16, No. 4, 411-425, 2011. 
[50] B. K. Kim, H. R. Park, \& J. W. Development of comic books and an animation as dietary education materials for children. Korean Journal of Community Nutrition, Vol. 13, No. 5, 630-639, 2008

[51] H. N. Son, M. J. Park, \& J. S. Han. A study on dietary habits and food frequency of young children who like sweets. Journal of the Korean Dietetic Association, Vol. 15, No. 1, 10-2, 2009.

[52] S. A. Mani, A. A. Aziz, J. John, \& N. M. Ismail. Knowledge, attitude and practice of oral health promoting factors among caretakers of children attending day-care centers in Kubang Kerian, Malaysia: A preliminary study. Journal of Indian Society of Pedodontics and Preventive Dentistry, Vol, 28, No. 2, 78, 2010.

[53] G. Nyberg, E. Sundblom, A. Norman, \& L. S. Elinder. A healthy school start-Parental support to promote healthy dietary habits and physical activity in children: Design and evaluation of a cluster-randomised intervention. BMC Public Health, Vol. 11, No. 1, 185, 2011.

[54] M. Hong, M. S. Choi, Y. H. Han, \& T. Hyun. Effect of nutrition education program developed by a public health center on preschool children's nutrition knowledge and dietary habits and the parent's dietary attitudes. Korean Journal of Community Nutrition, Vol. 15, No. 5, 593-602, 2010.

[55] C. Hu, D. Ye, Y. Li, Y. Huang, L. Li, Gao, Y., \& S. Wang. Evaluation of a kindergarten-based nutrition education intervention for pre-school children in China. Public health nutrition, Vol. 13, No. 2, 253-260, 2010.

[56] M. L. Hoffmann. Affect, cognition, and motivation. In R. M. Sorrentino \& E. T. Higgins (Eds.), Handbook of motivation and cognition. Foundations of social behavior (pp. 244-280). New York, NY: Guilford Press, 1986.

[57] H. W. Ker. Open the Book, and Train the Kong-fu of Self Learning--Ker Hua-wei's Talking about Reading Comprehension Cultivation; Parent-Child CommonWealth Magazine, No.39, October, 2012, from http://www.parenting .com.tw/article/article.action?id=5043783, 2012.

[58] J. S. Lee, Y. S. Choi, \& B. S. Bae. Association between nutritional knowledge and dietary behaviors of middle school children and their mothers. Korean Journal of Nutrition, Vol. 44, No. 2, 140-151, 2011.

[59] V. Swanson, K. G. Power, I. K. Crombie, L. Irvine, K. Kiezebrink, W. Wrieden, \& P. W. Slane. Maternal feeding behaviour and young children's dietary quality: A cross-sectional study of socially disadvantaged mothers of two-year old children using the Theory of Planned Behaviour. Int J Behav Nutr Phys Act, Vol. 23, 8-65, 2011.

[60] X. Guo, L. Zheng, Y. Li, S. Yu, G. Sun, H. Yang, H., ... \& Y. Sun. Differences in lifestyle behaviors, dietary habits, and familial factors among normal-weight, overweight, and obese Chinese children and adolescents. Int JBehav Nutr Phys Act, Vol. 9, No. 1, 120, 2012.

[61] Y. L. Cheng. Case Study of Intervention of Picture Book Teaching into Children with Development Retardation's Peer Interaction; Special Education Quartly, Vol. 124,37-54, 2012.

[62] Y. C. Chen. Research on Exerting Picture Books to Guide Children's Eating Habit--Take Certain Public Kindergarten in Taichung City as Example; Department of Early Childhood Education in National Taichung Education University; unpublished Master Thesis, Taichung City, 2010.

[63] L. Lautenschlager, \& C. Smith. Understanding gardening and dietary habits among youth garden program participants using the Theory of Planned Behavior. Appetite, Vol. 49, No. 1, 122-130, 2007.

[64] L. D. Ritchie, S. D. Whaley, P. Spector, J. Gomez, \& P. B. Crawford. Favorable impact of nutrition education on California WIC families. Journal of Nutrition Education \& Behavior, Vol. 42, No. 3, 2-10, 2010.

[65] Z. Mohd Shariff, , B. Abu Samah, L. Paim, M. Ismail, M. S. Kasim, N. Othman, N., ... \& Z. Azhar. Nutrition education intervention improves nutrition knowledge, attitude and practices of primary school children: a pilot study. International Electronic Journal of Health Education, Vol. 11, No. 1, 119-132, 2008.

[66] K. S. Choi. A study on nutrition knowledge, dietary attitudes and nutrition education needs among child-care teachers. Korean Journal of Community Nutrition, Vol. 15, No. 1, $137-148,2010$ 